\title{
SURFACE ROUGHNESS OF ROOT CANAL DENTIN FOLLOWING MECHANICAL PREPARATION USING DIFFERENT ENDODONTIC FILE SYSTEMS
}

\author{
Ayman M. Elkady* and Elsayed Gad**
}

\begin{abstract}
Introduction: This study was conducted to determine the surface topography of root canal dentin after mechanical preparation using different endodontic file systems.

Methodolgy: Twenty single rooted extracted premolars were used. After teeth decoronation, all roots were divided into four groups (five roots each). Group PNX was instrumented by ProTaper Next files, Group W was instrumented by Wave One. Group P was instrumented by Protaper files, and Group $\mathrm{H}$ (control) was instrumented by $\mathrm{K}$ type hand files. Radicular preparation for all groups was performed according to the each file system's manufacturer instructions. Roots were split longitudinally in a bucco-lingual direction giving a total of 10 specimens for each group. Samples of each group were photographed at cervical, middle and apical regions of each prepared canal using USB Digital microscope.
\end{abstract}

Results: Group P showed the highest roughness mean value followed by group H then group PNX while group $\mathrm{W}$ recorded the lowest value. The difference between groups was statistically significant. There was no significant difference between group PNX and group W. Apical regions recorded the highest roughness mean value followed by middle regions while cervical region recorded the lowest roughness mean value.

Conclusions: The use of Protaper file system showed the highest root canal roughness while Wave One file system showed the lowest values. Root canal apical regions showed higher roughness mean values than middle or cervical regions in all groups.

KEYWORDS: Dentin Roughness, NiTi, Rotary, Reciprocation.

\section{INTRODUCTION}

Root canal preparation as well as disinfection target to eliminate inorganic and organic tissue from inside the root canals (including a thin layer of intra-canal dentin), nullify endotoxins inside the dentin, lessen the number of microorganisms and prepare the root canal for appropriate filling.

* Associate Professor, Restorative Dentistry Department, Faculty of Dentistry, Consultant endodontist, Egypt.

** Assistant Professor, Dental Biomaterials Department, Faculty of Dentistry, Mansoura University, Egypt. 
The aim of root canal obturation is to afford a three-dimensional seal of root canal system, thus stopping bacterial entry from the oral cavity and peri-radicular tissues. In addition, the filling materials might seal the root canal system and can be operative in deactivating irritants that were not detached during root canal preparation ${ }^{1-3}$.

The hosting of nickel-titanium rotary files signifies a key jump in the development of endodontic instruments with an extensive diversity of refined instruments presently obtainable ${ }^{4,5}$. The super elastic alloy has made it conceivable to produce highly effectual instruments that can be rotated securely, even in curved root canals with a reasonable angulation, practically preserving the long axis of the canal in its original position. Since then, many different file designs have been tried and announced with disparities in rake angle, radial lands scheme, helical area, or thinness of the core. Some designs are highly aggressive and some are more flexible, whereas others offer safe tips or an intervallic helical angle ${ }^{6-11}$. Modern improvements in nickel-titanium metallurgy are also encouraging a potential for more elastic instruments ${ }^{12}$.

Adhesion encompasses interactions at the border between materials and depends on numerous features such as cleanliness, structure, and coarseness of adherent surface. Mechanical bonding is the most operative means of generating durable joints. In this category of adhesion, the material infiltrates into the adherent, becoming mechanically interconnected at some level. To accomplish effective adhesive bonding, it is imperative that the adherent have an uncontaminated and rough surface ${ }^{13}$. Appropriate root canal sealer adaptation to the root canal walls is a significant factor in the accomplishment of a fluid-tight seal ${ }^{4-15}$.

A root canal wall with greater roughness could encourage an improved contact between dentin and sealer which could advantage the obturation. Adhesive materials must come into bosom linking with the substrate to expedite molecular attraction and permit either chemical adhesion or infiltration for micromechanical surface attachment. The adhesion processes are principally prejudiced by the relative surface free energy (wetting ability) of the hard surface ${ }^{16-18}$.

The significance of roughness studies is reinforced due to the solid association between surface structure and its effect on dentin wettability, a property that impacts the bonding of the dental materials and microorganism adhesion ${ }^{19,20}$. To date, there have been no studies evaluating the effect of different types of root canal files and file systems on root canal dentin roughness.

The purpose of the present study was to evaluate the surface roughness topography of root canal dentin following mechanical preparation using different endodontic files and file systems.

\section{MATERIALS AND METHODS}

A total of 20 intact human mandibular single rooted premolars extracted for orthodontic purpose were used in the current study. Teeth were stored in saline after the tissue remnants on root surfaces were cleaned. Decoronation of teeth were done using high speed diamond abrasives (Diatech, Swiss Dental Instruments, Heerbrugg, Switzerland) with water spray cooling, then all roots were divided into four groups (five roots each). Group PNX was instrumented by nickel titanium NiTi rotary ProTaper Next files (Dentsply, Maillfer, Balligues, Switzerland), Group W was instrumented by NiTi reciprocating Wave One files (Dentsply, Maillfer, Balligues, Switzerland). Group P was instrumented by NiTi rotary ProTaper files (Dentsply, Maillfer, Balligues, Switzerland) and Group H (control) was instrumented by stainless steel (St.St.) K type hand files (Dentsply, Maillfer, Balligues, Switzerland).

Radicular preparation for all groups was performed according to each file system's manufacturer instructions; group PNX was prepared starting with $\mathrm{X} 1$ and finished with $\mathrm{X} 3$ file, group W was prepared by Primary file, group $\mathrm{P}$ was prepared starting with SX and finished with F2 file, and group $\mathrm{H}$ was prepared starting with file \#15 reaching master apical file \#30 then step 
back preparation till file \#45. Sodium hypochlorite $(5.25 \%)$ was used in all groups as an intracanal irrigant. Glyde paste was also used to reduce the risk of instrument fracture by acting as intracanal lubricant as well as smear layer removal (Dentsply, Maillfer, Balligues, Switzerland). By the use of a diamond disk (Diamant, Horico, Berlin, Germany) with air-water coolant at low speed, the prepared roots were then split longitudinally through the root canals in a bucco-lingual direction, resulting in two equal root halves giving a total of 10 specimens for each group (40 specimens total for all groups).

Samples were air dried then photographed at cervical, middle as well as apical regions of each prepared canal using USB Digital microscope attached camera (Scope Capture Digital Microscope, Guangdong, China) connected to a compatible PC, using a fixed magnification of $120 \mathrm{X}$.

Images were recorded with a resolution of 1280 $\times 1024$ pixels per image. Digital microscope images were cropped to $350 \times 400$ pixels using Microsoft office picture manager to specify/standardize area of roughness measurement. The cropped images were analyzed using WSxM software (Ver. 5 develop 4.1, Nanotec, Electronica, SL) ${ }^{21}$. Within the WSxM software, all limits, sizes, frames and measured parameters are expressed in pixels. Therefore, system calibration was done to convert the pixels into absolute real world units. Calibration was made by comparing an object of known size (a ruler in this study) with a scale generated by the software.

Subsequently, a 3D image at an area of $10 \mu \mathrm{m}$ $\times 10 \mu \mathrm{m}$ of the surface profile of all specimens were collected at cervical, middle as well as apical regions of each prepared canal.

WSxM software was used to calculate the roughness average ( $\mathrm{Ra}$ ) expressed in $\mu \mathrm{m}$, which can be assumed to be reliable indices of surface roughness $^{22}$.

Data analysis was performed in several steps. Initially, descriptive statistics for each group results. Two way analysis of variance ANOVA test of significance comparing variables affecting mean values (instruments and radicular regions). One way ANOVA followed by pair-wise Tukey's post-hoc tests were performed to detect significance between instrument/radicular region variable within each group. Statistical analysis was performed using Assistat 7.6 statistics software for Windows (Campina Grande, Paraiba state, Brazil). P values $\leq 0.05$ are considered to be statistically significant in all tests. The null hypothesis of the study was that there is no difference regarding the analyzed variables.

\section{RESULTS}

Roughness average $(\mathrm{Ra})$ results (Mean $\pm \mathrm{SD}$ ) as function of instrument type and radicular region are summarized in table (1) and graphically drawn in figure (1).

Microscopic 3D profile images for all groups with different regions; cervical (a), middle (b) and apical (c) are shown in figures (2-5).

Effect of instrument: Regardless to radicular region, it was found that group P recorded the highest roughness average mean value followed by group $\mathrm{H}$ then group PNX while group W recorded the lowest roughness average mean value. The difference between groups was statistically significant as indicated by two way ANOVA $(\mathrm{P}<0.05)$. Pair-wise Tukey's post-hoc showed non-significant $(\mathrm{P}>0.05)$ difference between group PNX and group W.

Effect of radicular region: Irrespective of instrument, it was found that apical region recorded the highest roughness average mean value followed by middle region, while cervical region recorded the lowest roughness average mean value. The difference between regions was statistically significant as indicated by two way ANOVA $(\mathrm{P}<0.05)$. Pair-wise Tukey's post-hoc showed non-significant ( $\mathrm{P}>0.05)$ difference between cervical and middle regions. The null hypothesis is therefore rejected as there was a statistical difference regarding the analyzed variables. 
TABLE (1) Roughness results (Mean $\pm \mathrm{SD}$ ) as function of instrument type and radicular regions:

\begin{tabular}{|c|c|c|c|c|c|}
\hline \multirow{2}{*}{\multicolumn{2}{|c|}{ Variables }} & \multicolumn{3}{|c|}{ Radicular region } & \multirow{3}{*}{$\begin{array}{c}\text { ANOVA } \\
\text { P value } \\
0.0119 *\end{array}$} \\
\hline & & \multirow{2}{*}{$\begin{array}{c}\text { Cervical } \\
0.2368^{\mathbf{B}}{ }_{\mathbf{b}} \pm 0.002\end{array}$} & \multirow{2}{*}{$\begin{array}{c}\text { Middle } \\
0.2391^{\mathrm{B}}{ }_{\mathrm{ab}} \pm 0.001\end{array}$} & \multirow{2}{*}{$\begin{array}{c}\text { Apical } \\
0.2399^{\mathrm{C}}{ }_{\mathrm{a}} \pm 0.0003\end{array}$} & \\
\hline \multirow{4}{*}{ Groups } & Group PNX & & & & \\
\hline & Group W & $0.2359^{\mathrm{B}}{ }_{\mathrm{b}} \pm 0.002$ & $0.2371^{\mathrm{B}}{ }_{\mathrm{ab}} \pm 0.003$ & $0.2416_{\mathrm{a}}^{\mathrm{BC}} \pm 0.003$ & $0.0257 *$ \\
\hline & Group P & $0.2421_{\mathrm{b}}^{\mathrm{A}} \pm 0.004$ & $0.2442^{\mathrm{A}}{ }_{\mathrm{b}} \pm 0.002$ & $0.2499_{\mathrm{a}}^{\mathrm{A}} \pm 0.001$ & $0.0008 *$ \\
\hline & Group H & $0.2406_{\mathrm{a}}^{\mathrm{A}} \pm 0.002$ & $0.2402^{\mathrm{A}} \pm 0.002$ & $0.2439^{\mathrm{B}}{ }_{\mathrm{a}} \pm 0.003$ & $0.1041 \mathrm{~ns}$ \\
\hline ANOVA & P value & 0.0079* & $0.0016 *$ & $<0.0001 *$ & \\
\hline
\end{tabular}

Columns - different upper case letters indicating significant difference between instrument groups $(p<0.05)$

Rows - different lower case letters indicating significant difference between regions $(p<0.05)$

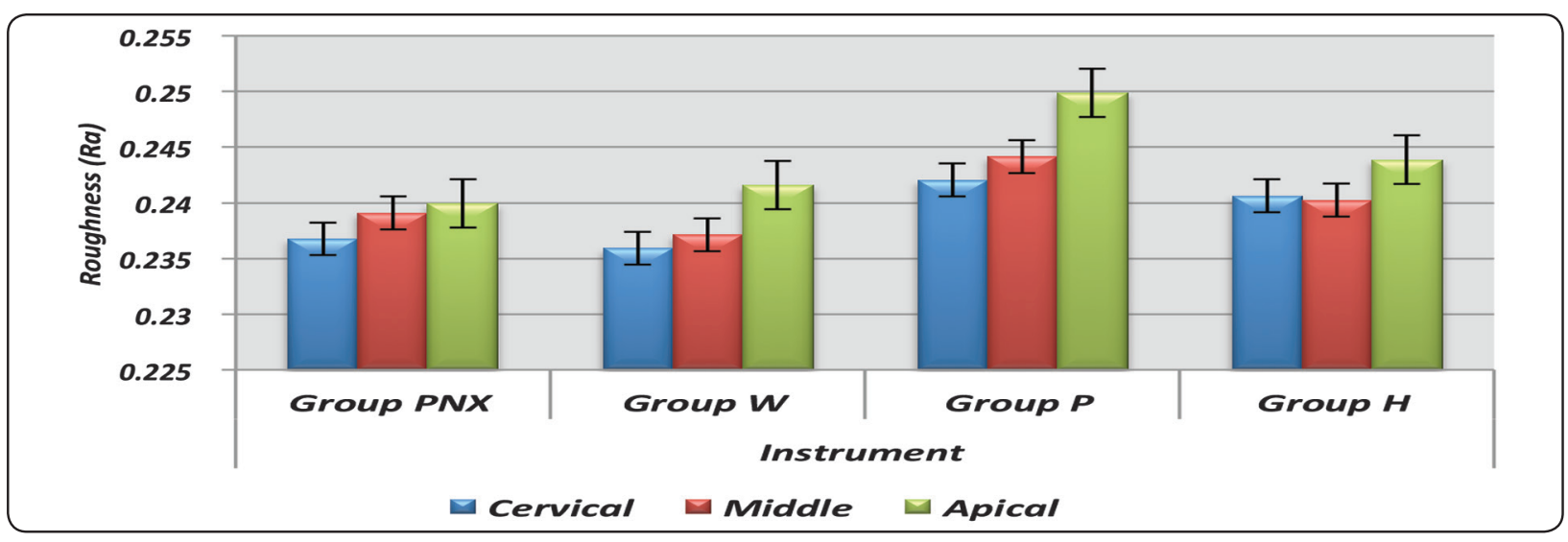

Fig. (1) Histogram of roughness mean values as function of instrument type and radicular regions.

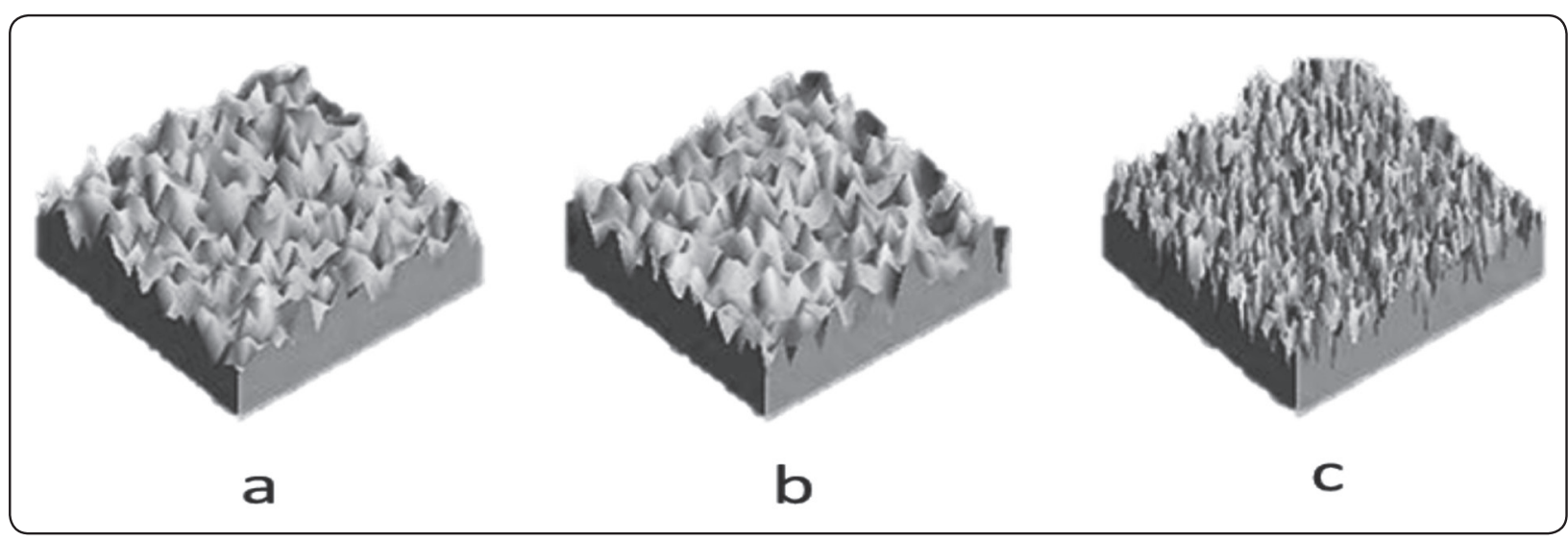

Fig. (2) Microscopic 3D profile images for group PNX (Protaper Next files) with different regions; cervical (a), middle (b) and apical (c). 


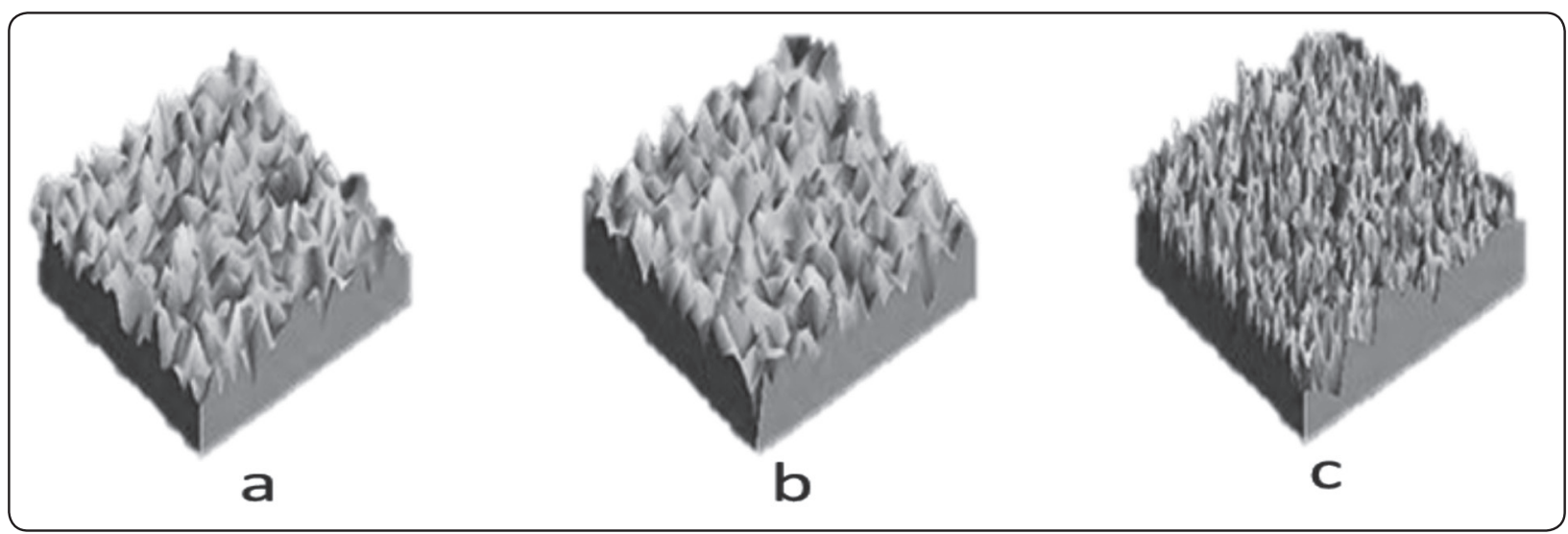

Fig. (3) Microscopic 3D profile images for group W (Wave One files) with different regions; cervical (a), middle (b) and apical (c).

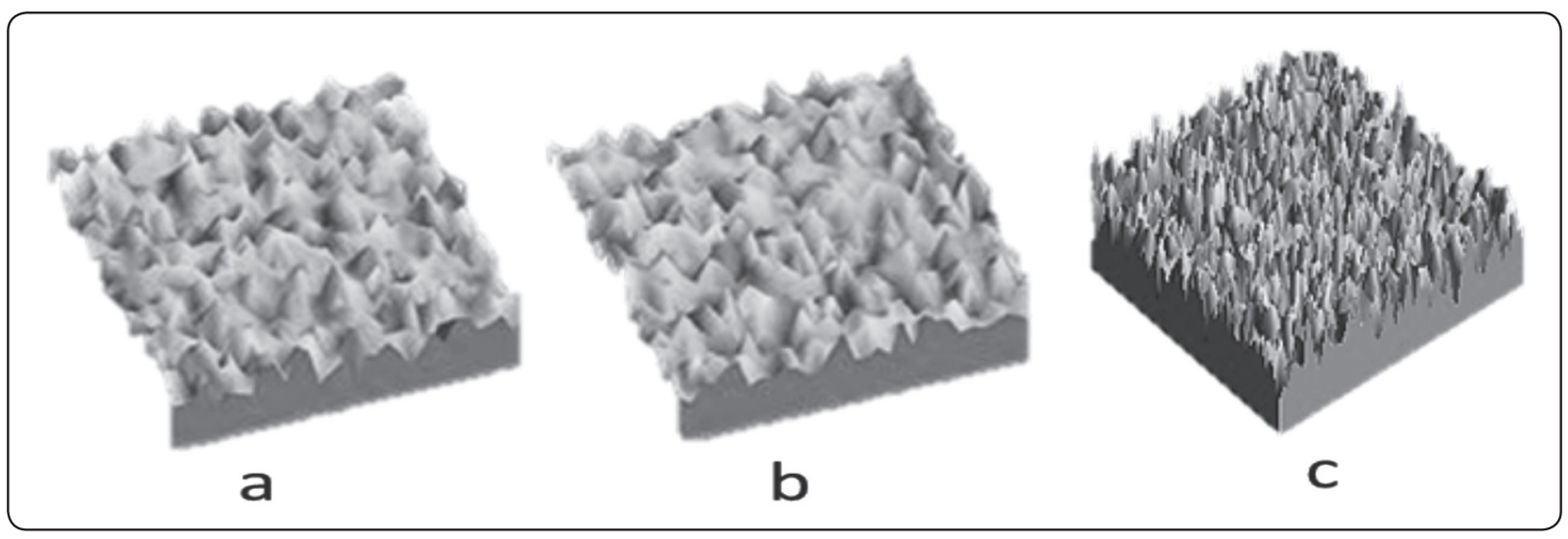

Fig. (4) Microscopic 3D profile images for group P (Protaper files) with different regions; cervical (a), middle (b) and apical (c).

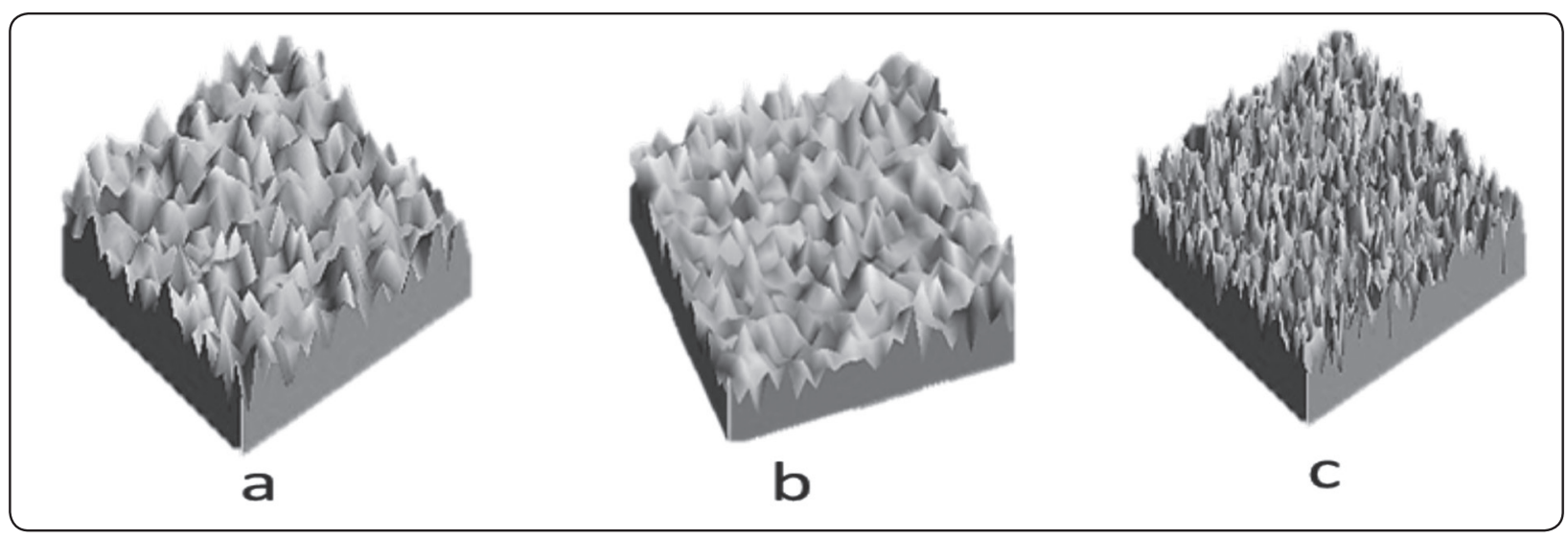

Fig. (5) Microscopic 3D profile images for group H (Hand files; K) with different regions; cervical (a), middle (b) and apical (c). 


\section{DISCUSSION}

In the current study, topographic surface changes of root canal dentin (cervical, middle and apical) were measured after mechanical root canal preparation with different filing systems. Many articles tackled root canal roughness as a result of using intracanal chemical irrigants ${ }^{23-31}$ while roughness tests as a result of mechanical root canal preparation with different filing systems are not conducted as yet.

Selection of different mechanical preparation root canal filing systems for the current study was done; normal rotary file motion (Protaper), swaggering rotary file motion (Protaper Next) and reciprocating file motion (Wave One). Hand filing roughness mean values (step back with $\mathrm{K}$ files) were used as control as they are being used popularly with high success rates for long time.

Apical region recorded the highest roughness average mean value followed by middle region while cervical region recorded the lowest value. These results are considered to be in favor of root canal treatment success, as high roughness values improve adhesion. In agreement, different articles ${ }^{16-18}$ high mentioned the importance of root canal roughness and surface energy for the success of adhesion of the filling material to the dentinal wall of the root canal.

Also, the highest roughness values were recorded after using Protaper as well as $\mathrm{K}$ hand files while the lowest roughness values were recorded after using Protaper Next and Wave One file systems.

In the present study, USB digital microscope with a built in camera connected to a personal computer was used to test and record surface roughness. The method proofed to be easy and reliable.

Using the typical method for preparation of dentin samples in Scanning Electron Microscopy (SEM), the sample is dehydrated in graded acetone succession, dried and layered in sputtering device after its fixation. The manifestation of artefacts initiated by shrinking cannot be eradicated in practice because dentin toughly delicate to dehydration ${ }^{32}$. Also, one of the main disadvantages of using SEM is that the roughness results are only qualitative and not quantitative.

Atomic force microscope (AFM) was also used ${ }^{33-36}$ for the same purpose giving quantitative readings but in a more complex way than the USB microscope.

Based on the findings of the current study, it may be concluded that the use of Protaper file system could bring better adhesion between the dentinal walls of the root canal and different obturation materials. Also, the present work proofed that mechanical preparation of root canals, no matter which file system is used, showed the highest roughness values at the root canal apical segment than middle as well as cervical segments. This finding came in favor with the success rate of root canal treatment.

\section{REFERENCES}

1. Schilder H. Filling root canals in three dimensions. Dent Clin North Am 1967; 723-44.

2. Skidmore LJ, Berzins DW, Bahcall JK. An in vitro comparison of the intraradicular dentin bond strength of Resilon and gutta-percha. J Endod 2006; 32: 963-6.

3. Siqueira JF Jr, $\mathrm{R}^{\wedge} \mathrm{Oc}_{s}$ as IN, Valois CR. Apical sealing ability of five endodontic sealers. Aust Endod J 2001; 27: 33-5.

4. Esposito PT, Cunningham CJ. A comparison of canal preparation with nickel titanium and stainless steel instruments. J Endod 1995; 21: 173-6.

5. Walia H, Brantley WA, Gerstein H. An initial investigation of the bending and torsional properties of nitinol root canal files. J Endod 1988; 14: 346-51.

6. Blum J-Y, Machtou P, Ruddle C, et al. Analysis of mechanical preparations in extracted teeth using ProTaper rotary instruments: value of the safety quotient. J Endod 2003; 29: 567-75.

7. González-Rodríguez M, Ferrer-Luque C. A comparison of Profile, Hero 642, and K3 instrumentation systems in teeth 
using digital imaging analysis. Oral Surg Oral Med Oral Pathol Oral Radiol Endod 2004; 97: 112-5.

8. Schafer E, Vlassis M. Comparative investigation of two rotary nickel-titanium instruments: ProTaper versus RaCe. Part 2. Cleaning effectiveness and shaping ability in severely curved root canals of extracted teeth. Intern Endod J 2004; 37: 239-48.

9. Rangel S, Cremonese R, Bryant S, et al. Shaping ability of RaCe rotary nickel-titanium instruments in simulated root canals. J Endod 2005; 31: 460-3.

10. Peters OA. Challenges in root canal preparation. J Endod 2004; 30: 559-67.

11. Hu“ lsmann M, Peters OA, Dummer PMH. Mechanical preparation of root canals: shaping goals, techniques and means. Endod Topics 2005; 10: 30-76.

12. Johnson E, Lloyd A, Kuttler S, et al. Comparison between a novel nickel-titanium alloy and $508 \mathrm{Nitinol}$ on the cyclic fatigue life of ProFile 25/.04 rotary instruments. J Endod 2008; 34: 1406-9.

13. Marshall SJ, Bayne SC, Baier R, Tomsia AP, Marshall GW. A review of adhesion science. Dent Mater 2010; 26: 11-6.

14. Saleh IM, Ruyter IE, Haapasalo M, Ørstavik D. The effects of dentin pre-treatment on the adhesion of root canal sealers. Intern Endod J 2002; 35: 859-66.

15. Kokkas AB, Boutsioukis Ach, Vassiliadis LP, Stavrianos $\mathrm{CK}$. The influence of the smear layer on dentinal tubule penetration depth by three different root canal sealers: An in vitro study. J Endod 2004; 30: 100-2.

16. Erickson RL. Surface interactions of dentin adhesive materials. Oper Dent 1992; 5: 81-94.

17. Eick JD, Gwinnett AJ, Pashley DH, Robinson SJ. Current concepts on adhesion to dentin. Crit Rev Oral Biol Med 1997; 8: 306-35.

18. Al-Omari WM, Mitchell CA, Cunningham JL. Surface roughness and wettability of enamel and dentine surfaces prepared with different dental burs. J Oral Rehabil 2001; 28: 645-50.

19. Eick JD, Johnson LN, Fromer JR, Good RJ, Neumann AW. Surface topography: its influence on wetting and adhesion in a dental adhesive system. J Dent Res 1972; 51: 780-8.

20. Tang L, Pillai S, Revsbech NP, Schramm A, Bischoff C, Meyer RL. Biofilm retention on surfaces with variable roughness and hydrophobicity. Biofouling 2011; 27: 111-21.
21. Horcas I, Fernandez R, Gomez JM, Colchero J, GomezHerrero J, Baro AM. WSXM: A software for scanning probe microscopy and a tool for nanotechnology. Rev Sci Instr 2007 Jan; 78(1): 013705.

22. Kakaboura A, Fragouli M, Rahiotis C, et al. Evaluation of surface characteristics of dental composites using profilometry, scanning electron, atomic force microscopy and gloss-meter. J Mater Sci Mater Med 2007; 18: 155-63.

23. Ring KC, Murray PE, Namerow KN, Kuttler S, GarciaGodoy F. The comparison of the effect of endodontic irrigation on cell adherence to root canal dentin. J Endod 2008; 34: 1474-9.

24. Ulusoy Öİ, Görgül G. Effects of different irrigation solutions on root dentine microhardness, smear layer removal and erosion. Aust Endod J 2013; 39: 66-72.

25. Ari $\mathrm{H}$, Yaşar E, Belli S. Effects of $\mathrm{NaOCl}$ on bond strengths of resin cements to root canal dentin. J Endod 2003; 29: 248-51.

26. Hu X, Ling J, Gao Y. Effects of irrigation solutions on dentin wettability and roughness. J Endod 2010; 36: 1064-7.

27. Yilmaz Z, Basbag B, Buzoglu HD, Gümüsderelioglu M. Effect of lowsurface tension EDTA solutions on the wettability of root canal dentin.Oral Surg Oral Med Oral Pathol Oral Radiol Endod 2011; 111: 109-14.

28. Marending M, Luder HU, Brunner TJ, Knecht S, Stark WJ, Zehnder M. Effect of sodium hypochlorite on human root dentine-mechanical, chemical and structural evaluation. Intern Endod J 2007; 40: 786-93.

29. Zhang K, Tay FR, Kim YK, Mitchell JK, Kim JR, Carrilho $\mathrm{M}$, et al. The effect of initial irrigation with two different sodium hypochlorite concentrations on the erosion of instrumented radicular dentin. Dent Mater 2010; 26: 514-23.

30. Estrela C, Estrela CR, Barbin EL, Spanó JC, Marchesan MA, Pécora JD. Mechanism of action of sodium hypochlorite. Braz Dent J 2002; 13: 113-7.

31. Aranda-Garcia AJ, Kuga MC, Chavéz-Andrade GM, Kalatzis-Sousa NG, Hungaro Duarte MA, Faria G, et al. Effect of final irrigation protocols on microhardness and erosion of root canal dentin. Microsc Res Tech 2013; 76:1079-83.

32. Perdigão J, Thompson J, Toledano M et al. An ultra-morphological characterization of collagen-depleted etched dentin. Am J Dent 1999; 12: 250-5. 
33. Feninat El, Ellis F, Sacher TH. A tapping mode AFM study of collapse and denaturation in dentinal collagen. Dent Mater 2001; 17: 284-8.

34. Marshall GW, Saeki K, Gansky SA, et al. AFM study of citric acid ferric chloride etching characteristics of dentin. Am J Dent 1999; 12: 2716.
35. Oliveira SS, Marshall JS, Hilton JF et al. Etching kinetics of self etching primer. Biomater 2002; 23: 410512.

36. Van Meerbeek B, Yoshida Y, Snauwaert J, et al. Hybridization effectiveness of a two step versus three step smear layer removing adhesive system examined correlatively by TEM and AFM. J Adhes Dent 1999; 1: 723. 